\title{
Heterogeneity of Prevalence of Social Media Addiction Across Multiple Classification Schemes: Latent Profile Analysis
}

\author{
Cecilia Cheng ${ }^{1}$, PhD; Omid V Ebrahimi ${ }^{2,3}$, MSc; Jeremy W Luk ${ }^{4}, \mathrm{PhD}$ \\ ${ }^{1}$ Department of Psychology, The University of Hong Kong, Pokfulam, Hong Kong \\ ${ }^{2}$ Department of Psychology, University of Oslo, Oslo, Norway \\ ${ }^{3}$ Research Institute, Modum Bad Psychiatric Hospital, Vikersund, Norway \\ ${ }^{4}$ National Institute on Alcohol Abuse and Alcoholism, Bethesda, MD, United States
}

\section{Corresponding Author:}

Cecilia Cheng, PhD

Social and Health Psychology Lab

Department of Psychology

The University of Hong Kong

Pokfulam

China (Hong Kong)

Phone: 85239174224

Email: ceci-cheng@hku.hk

\section{Abstract}

Background: As social media is a major channel of interpersonal communication in the digital age, social media addiction has emerged as a novel mental health issue that has raised considerable concerns among researchers, health professionals, policy makers, mass media, and the general public.

Objective: The aim of this study is to examine the prevalence of social media addiction derived from 4 major classification schemes (strict monothetic, strict polythetic, monothetic, and polythetic), with latent profiles embedded in the empirical data adopted as the benchmark for comparison. The extent of matching between the classification of each scheme and the actual data pattern was evaluated using sensitivity and specificity analyses. The associations between social media addiction and 2 comorbid mental health conditions_-depression and anxiety_were investigated.

Methods: A cross-sectional web-based survey was conducted, and the replicability of findings was assessed in 2 independent samples comprising 573 adults from the United Kingdom (261/573, 45.6\% men; mean age 43.62 years, SD 12.24 years) and 474 adults from the United States (224/474, 47.4\% men; mean age 44.67 years, SD 12.99 years). The demographic characteristics of both samples were similar to those of their respective populations.

Results: The prevalence estimates of social media addiction varied across the classification schemes, ranging from $1 \%$ to $15 \%$ for the UK sample and $0 \%$ to $11 \%$ for the US sample. The latent profile analysis identified 3 latent groups for both samples: low-risk, at-risk, and high-risk. The sensitivity, specificity, and negative predictive values were high (83\%-100\%) for all classification schemes, except for the relatively lower sensitivity (73\%-74\%) for the polythetic scheme. However, the polythetic scheme had high positive predictive values (88\%-94\%), whereas such values were low (2\%-43\%) for the other 3 classification schemes. The group membership yielded by the polythetic scheme was largely consistent (95\%-96\%) with that of the benchmark.

Conclusions: Among the classification schemes, the polythetic scheme is more well-balanced across all 4 indices.

(J Med Internet Res 2022;24(1):e27000) doi: $\underline{10.2196 / 27000}$

\section{KEYWORDS}

behavioral addiction; compulsive social media use; information technology addiction; mental health; psychological assessment; sensitivity; social network site; social networking; well-being 


\section{Introduction}

\section{Background Context}

The internet has turned the world into an interconnected, global village in which information and problems alike spread swiftly across countries. Apart from face-to-face interactions, social media has emerged as a major channel of interpersonal communication in the cyber age. Social media use is beneficial in many aspects. For instance, social media allows people to maintain contact with existing friends or family members who live apart [1,2], and individuals who use social media to connect with their social network members tend to experience greater levels of subjective well-being $[3,4]$. In the extended period of social distancing during the COVID-19 pandemic, social media use is found to be associated with both social and physical well-being [5,6]. For people who seek mental health professional services, the interventions delivered through social media are deemed more accessible and engaging than face-to-face interventions [7].

Despite these psychological benefits, the misuse of social media can incur considerable psychological costs, especially for individuals who use social media as a refuge to evade unpleasant feelings or real-life problems. According to the model of compensatory internet use [8], social media use may improve these individuals' psychological condition in the short run, but such short-term benefits may also strengthen their dependence on social media, leading to continuous excessive use of social media and the development of social media addiction [9]. Moreover, social media addiction is motivated by the need to fulfill fundamental psychological needs that cannot be gratified in the real world, such as the need to belong [10-13].

\section{Social Media Addiction and Its Assessment}

Social media addiction is a type of behavioral addiction that is broadly defined as compulsive engagement in social media platforms that significantly disrupts the users' functioning in important life domains, such as interpersonal relations, work or study performance, and physical health $[14,15]$. According to the components model of behavioral addiction [16], social media addiction is conceptualized as a set of symptoms pertaining to six types of problematic behavior: (1) salience, which refers to the dominance of social media activities in one's thoughts and daily life; (2) tolerance, which refers to the tendency of spending an increasing amount of time using social media to attain the same amount of pleasure; (3) mood modification, which refers to the use of social media to avoid or mitigate unpleasant emotions experienced in real-life events; (4) relapse, which refers to the failure of curbing excessive social media use after attempts of abstinence or control; (5) withdrawal, which refers to psychological distress experienced when one cannot get access to social media; and (6) conflict, which refers to the adverse impact on one's job or studies because of problematic social media use.

Although social media addiction is not currently a diagnosable condition, researchers have constructed measures of social media addiction based on the diagnostic criteria for other behavioral addictions such as gambling disorder [16,17]. The most popular ones include the Facebook Intrusion Questionnaire [18] and the
Bergen Social Media Addiction Scale (BSMAS) [19]. The former measure assesses addiction specific to a single social media platform, whereas the latter assesses addiction to social media in general. Instead of creating new assessment tools, another group of researchers have modified the current validated scales of internet addiction. The modification typically involves altering the context from Internet to Facebook or social media. For instance, the items of the Problematic Facebook Use Scale [20] were adapted from those of the Generalized Problematic Internet Use Scale [21].

\section{Classification Schemes for Social Media Addiction}

Validated measures of social media addiction have been widely used as screening tools for distinguishing individuals with and without the problem $[22,23]$. Both monothetic and polythetic formats have been adopted to yield prevalence estimates and to screen cases [24,25], because these schemes have long been used in case classifications of psychiatric disorders in the Diagnostic and Statistical Manual of Mental Disorders (DSM) $[17,26,27]$. The classical monothetic classification is generally regarded as more conservative because a positive diagnosis requires the endorsement of all the listed criteria [28]. For polythetic classification, however, no single criterion is required to make a diagnosis. The polythetic classification is more liberal than the monothetic classification because a positive diagnosis requires the endorsement of more than half of the listed criteria rather than all; therefore, individuals with the same classification may have different clinical presentations. Polythetic classification is commonly used in a variety of clinical diagnoses, including gambling disorder and substance abuse [17,27].

Most existing measures of social media addiction consist of items that are answered on a Likert-type scale ranging from 1 to 5 rather than dichotomous options. A usual practice for indicating the presence of a symptom involves the recoding of the 5-point ratings using the midpoint (ie, 3 ) as the cutoff such that a particular criterion is met for a score of 3 or above. Some researchers recently advocated stricter coding by setting a higher cutoff of 4 instead of the midpoint [29,30]. Taken together, a review of the literature reveals 4 commonly adopted classification schemes: monothetic, polythetic, strict monothetic, and strict polythetic. As these schemes vary in the extent of strictness in case classifications, different prevalence estimates are obtained, with higher prevalence yielded from more liberal classifications such as the polythetic scheme.

Previous studies on social media addiction have adopted either 1 or at most 2 of the classification schemes for deriving prevalence estimates, and the reported prevalence rates differ vastly across studies. As social media addiction is a global mental health concern, researchers worldwide have investigated the prevalence of this emergent problem [31-34]. The samples recruited in these prevalence studies vary considerably in their demographic characteristics, such as age and ethnicity, making between-study comparisons difficult. This study is the first to apply all 4 major classification schemes such that comparisons of the prevalence drawn from various schemes can be made. A total of 2 independent, demographically heterogeneous samples 
were included to evaluate the extent of cross-sample replicability in the findings.

\section{Evaluation of Classification Schemes for Social Media Addiction}

Sensitivity and specificity analyses are widely used for the evaluation of classification schemes [35]. This method seeks to test the performance of a classification in matching and predicting a diagnosis or outcome. As a gold standard for classifying social media addiction is currently unavailable, the latent profiles embedded in a data set are adopted as a benchmark to evaluate which existing classification scheme for social media addiction can provide the best fit to empirical data. Latent profile analysis (LPA) is a type of mixture modeling that can reveal hidden subgroups of individuals from observed data that share similar symptom profiles [36]. This person-centered statistical approach is especially appropriate for classifying disorders with heterogeneous symptoms, because highly consistent classifications can be obtained by precise distinctions among profiles and differences in characteristics among profiles [37,38]. LPA has been applied to social media addiction and can be used to estimate the proportion of the population with different risk levels of this disorder [39]. This study extends the literature by evaluating the extent to which the prevalence estimate derived from a particular classification approximates the latent profiles of symptoms actually endorsed by respondents, and the results are indicated by 4 indices: sensitivity, specificity, positive predictive value, and negative predictive value (Figure 1).

Figure 1. The 4 indicators of sensitivity and specificity analysis.

\section{Latent profile (from actual data)}

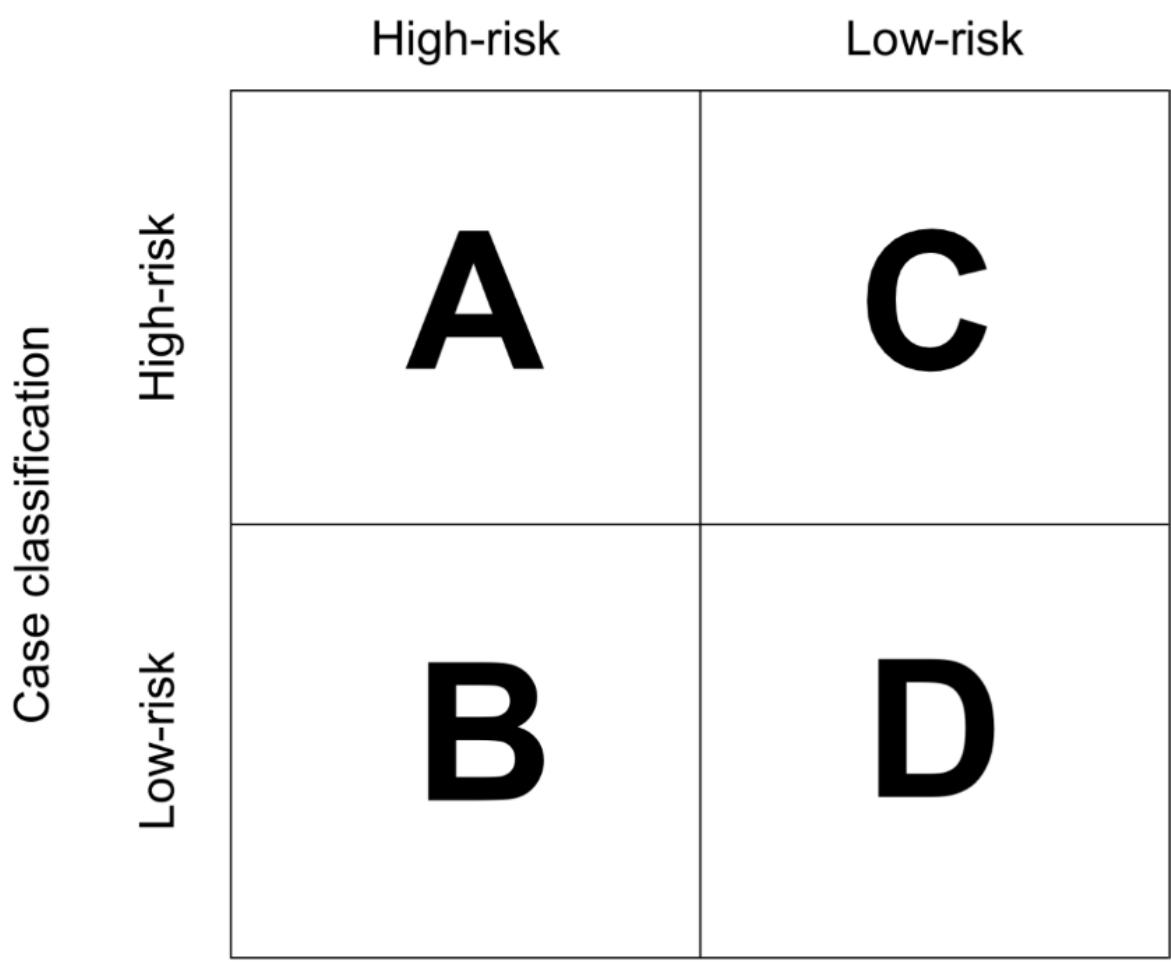

\section{Sensitivity $=A /(A+B)$ Positive predictive value $=A /(A+C)$ Specificity $=D /(C+D)$ Negative predictive value $=D /(B+D)$}

In this study, sensitivity refers to the proportion of individuals from the data-driven, latent high-risk group who are also classified by a particular scheme as high risk. Specificity refers to the proportion of individuals from the data-driven, latent low-risk group who are also classified by a particular scheme as low risk. Positive predictive value refers to the proportion of high-risk participants classified by a particular scheme who also belong to the data-driven, latent high-risk group. Negative predictive value refers to the proportion of low-risk participants classified by a particular scheme who also belong to the data-driven, latent low-risk group.

\section{Social Media Addiction and Comorbid Mental Health Problems}

To establish that social media addiction is not merely a normative behavioral pattern, it is important to evaluate whether it is associated with other comorbid mental health problems. In the literature on social media addiction, a frequently researched psychiatric condition is depression, which has been found to have positive associations with social media addiction. Specifically, individuals with depression tend to have a high risk of developing social media addiction [40,41]. Although 
users generally have more pleasant experiences than unpleasant ones when engaging in social media, unpleasant experiences on social media (eg, cyberbullying and social comparison with friends or strangers) tend to compromise mental health [42]. These adverse mental health impacts are especially salient among individuals with depression owing to their ruminative response style $[43,44]$.

Another frequently researched psychiatric condition is anxiety $[10,45]$. Some studies have shown that individuals with anxiety are prone to social media addiction because of their strong motivation to avoid face-to-face social interactions [46]. As individuals with social media addiction tend to spend more time on web-based than in-person social interactions, their prolonged social media use may erode social skills and promote greater fear of meeting people in real life [47]. Their anxiety may in turn aggravate their symptoms of social media addiction, as these individuals continue to perceive in-person interactions as a source of threat [46]. People who fear face-to-face communication experience a deficit in need for relatedness, which may arise from feelings of insecurity in daily life situations, and social media may thus be used as a compensational tool to gratify their relatedness needs [47]. Prolonged, excessive use of social media may lead to social media addiction among individuals with heightened anxiety [48].

\section{Methods}

\section{Participant Recruitment and Procedures}

The 2 independent samples for this study were recruited from Prolific because this web-based participant pool provides heterogeneous samples with diverse demographic characteristics. Moreover, the participants of this web-based survey platform were found to be more honest and naïve, and their data quality was better than that of members from other survey platforms [49]. Eligible participants were residents of the United Kingdom or the United States aged between 18 and 65 years and were users of at least one social networking site. To maintain data quality, only those who had an approval rating of $\geq 90 \%$ on the survey site were included.

The samples were recruited from the United Kingdom and the United States because members of both countries are the largest body of consumers of the English version of the BSMAS. These countries are appropriate for sample replication because they are highly similar in their internet penetration rates, socioeconomic development, and cultural values [50,51]. Recruitment was carried out from May 18, 2020, to May 24, 2020 .

All participants completed a set of questionnaires that was constructed and launched through a web-based survey tool, Qualtrics (Qualtrics International Incorporation). The research protocol of this study followed those adopted in previous web-based surveys [29,52]. An advertisement was placed on the survey platform, and those interested were invited to sign up. All participants had to give their consent before the survey began. Upon completion of the survey, they were paid according to the standard rate set by the survey platform. The human research ethics committee of the university where the principal author is employed approved the research protocol before this study was implemented.

\section{Measures}

\section{Social Media Addiction}

The symptoms of social media addiction were measured by the BSMAS [10], which is by far the most widely used validated assessment tool for addictive use of social media in general. This scale comprises 6 items, each measuring a core symptom (ie, salience, tolerance, mood modification, loss of control, withdrawal, and conflict). Item wording was consistent with the diagnostic criteria for gambling disorder [17]. The respondents rated each item on a 5-point scale, ranging from 1 (very rarely) to 5 (very often). The item scores were aggregated to obtain a composite score, and the 4 major classification schemes outlined in the Introduction section (the Classification Schemes for Social Media Addiction subsection) were adopted to categorize respondents into groups: high- versus noto-low-risk. Prevalence rate refers to the proportion of participants who were classified as having social media addiction to the entire sample, and the prevalence rates derived from various classification schemes were then compared. The BSMAS was a reliable measure in this study (Cronbach $\alpha=.88$ and .86 for the UK and the US samples, respectively).

\section{Depression}

In this study, depression and anxiety were included as criterion variables owing to the high comorbidity between social media addiction and both of these mental health conditions $[53,54]$. Probable depression was assessed using the Center for Epidemiological Studies Depression Scale [55], which was constructed for use with general, nonpsychiatric populations. Respondents were instructed to rate each of the 20 items on a 4-point scale ranging from 0 (rarely or none of the time) to 3 (most or all of the time). A higher composite score indicated a higher level of depression. This measure is widely adopted as a screening tool for clinical depression, with a recommended cutoff score of 16. This threshold score was thus adopted to indicate probable depression. The measure exhibited excellent psychometric properties in screening for major depression in the general population as verified by the DSM [55]. The depression measure displayed internal consistency in this study (Cronbach $\alpha=.92$ and .91 for the UK and the US samples, respectively).

\section{Anxiety}

Probable anxiety was measured by the state anxiety subscale of the State-Trait Anxiety Inventory Form Y1 [56], which was selected because this extensively validated measure has by far been the most popular screening tool for anxiety [57]. Respondents rated each of the 20 items on a 4-point scale ranging from 1 (not at all) to 4 (very much so). A higher composite score indicates a higher level of anxiety. According to the community adult norms stated in the manual [56], a cutoff score of 40 was used for screening. This measure was found to be reliable (Cronbach $\alpha=.96$ and .96 for the UK and the US samples, respectively). 


\section{Data Analysis}

LPA was conducted because this person-centered approach is currently widely applied for identifying latent groups with similar characteristics [58]. A total of 6 BSMAS items were included as indicator variables in this analysis. Multiple indices were checked to determine the model with the best fit of data [59]. Specifically, a number of models with different class solutions ( $k$ ranging from 2 to 5 ) were tested, and better data fit was indicated by lower values of 3 goodness-of-fit statistics: Bayesian Information Criterion, sample size adjusted Bayesian Information Criterion, and Akaike Information Criterion. Entropy was also examined to evaluate the precision of assigning latent group membership, with a value of $\geq 0.80$, indicating precision of classification. A class solution with an entropy value of $<0.80$ was ruled out. In addition, the Lo-Mendell-Rubin likelihood ratio test and bootstrap likelihood ratio test were used to assist model selection, and a significant result (ie, $P<.05$ ) showed that a $k$ class model improved a $k-1$ class model. If the results revealed that 2 or more models were adequate, model parsimony and interpretability were considered. After the model selection decision had been made, the profiles were plotted for each group using a line graph.

The latent profiles identified in the LPA were then mapped onto existing classification schemes using sensitivity and specificity analyses [60]. A total of 4 indices-sensitivity, specificity, positive predictive value, and negative predictive value-were examined (the Evaluation of Classification Schemes for Social Media Addiction subsection and Figure 1). In addition, an index of overall consistency was reported to indicate the percentage of overlap in group membership between the latent profiles and high-versus-low-risk groups classified by a particular scheme.
Risk ratio was used to make two types of estimation: (1) the individual contribution of demographic variables (sex and age groups) to the risk for social media addiction and (2) the individual contribution of social media addiction prevalence to the risk for mental health problems. All statistical analyses were conducted using SPSS version 26 (IBM), except for LPA, which was conducted using MPlus version 8.5 (Muthén and Muthén).

\section{Funding and Ethical Considerations}

This study was funded in part by the General Research Fund administered by the Research Grants Council of Hong Kong in January 2020 (grant 17400714). The research protocol was reviewed and approved by the human research ethics committee of the University of Hong Kong before data collection (approval number: EA2002033; approval date: March 4, 2020). All study procedures were performed in accordance with the ethical principles of the Declaration of Helsinki. All participants were required to provide informed consent before completing the survey.

\section{Results}

\section{Sample Characteristics}

The UK sample comprised 573 adults, whereas the US sample comprised 474 adults. The sample size of each country met the requirements for conducting covariance modeling [59] and sensitivity and specificity analyses [35]. The average age of the participants in the UK sample was 43.62 years (SD 12.24 years) and that of the participants in the US sample was 44.67 years (SD 12.99 years). Table 1 presents the sex and age distribution of the participants from both samples as well as those of the UK and the US populations. As shown in Table 1, sample distributions of these major demographic variables were comparable to those of their respective populations.

Table 1. Sex and age distribution of the 2 samples compared with that of their own population $(\mathrm{N}=1047)$.

\begin{tabular}{|c|c|c|c|c|}
\hline \multirow[t]{2}{*}{ Parameters } & \multicolumn{2}{|c|}{ The United Kingdom, n (\%) } & \multicolumn{2}{|c|}{ The United States, n (\%) } \\
\hline & Sample $(n=573)$ & Population in 2020 & Sample $(\mathrm{n}=474)$ & Population in 2020 \\
\hline \multicolumn{5}{|l|}{ Sex } \\
\hline Male & $261(45.6)$ & $33,821^{\mathrm{a}}(49.8)$ & $224(47.4)$ & $165,899^{\mathrm{a}}(50.1)$ \\
\hline Female & $312(54.4)$ & $34,065(50.2)$ & $250(52.6)$ & $165,104(49.9)$ \\
\hline \multicolumn{5}{|c|}{ Age group (years) } \\
\hline $18-34$ & $192(33.5)$ & $22,775(33.5)$ & $169(35.6)$ & $118,036(35.6)$ \\
\hline $35-49$ & $191(33.3)$ & $22,654(33.4)$ & $152(32.1)$ & $105,788(32)$ \\
\hline $50-65$ & $190(33.2)$ & $22,457(33.1)$ & $153(32.3)$ & $107,179(32.4)$ \\
\hline
\end{tabular}

${ }^{\mathrm{a}}$ Figures in these columns are expressed in thousands.

\section{Case Classification With LPA}

Table 2 presents the results of LPA that were tested and compared among the 4 models derived from different classification schemes. For the UK sample, the 3-class model was selected because the Lo-Mendell-Rubin likelihood ratio test showed that this model had better data fit than the 2-class model, but the degree of data fit was highly similar for the 3-class, 4-class, and 5-class models. Hence, the 3-class model was chosen for parsimonious considerations. 
Table 2. Summary of latent profile analysis comparing the various models $(\mathrm{N}=1047)$.

\begin{tabular}{|c|c|c|c|c|}
\hline \multirow[t]{2}{*}{ Characteristics } & \multicolumn{4}{|c|}{ Model comparison } \\
\hline & 2-class model & 3-class model & 4-class model & 5-class model \\
\hline \multicolumn{5}{|l|}{ The UK Sample $(n=573)$} \\
\hline $\mathrm{BIC}^{\mathrm{a}}$ & 8748.65 & 8196.68 & 8063.43 & 7882.23 \\
\hline SSABIC $^{\mathrm{b}}$ & 8688.33 & 8114.14 & 7958.67 & 7755.25 \\
\hline $\mathrm{AIC}^{\mathrm{c}}$ & 8665.99 & 8083.56 & 7919.85 & 7708.20 \\
\hline Entropy & 0.94 & 0.90 & 090 & 0.93 \\
\hline LMR-LRT $^{\mathrm{d}}, P$ value & .004 & .001 & .32 & .08 \\
\hline BLRT $^{\mathrm{e}}, P$ value & $<.001$ & $<.001$ & $<.001$ & $<.001$ \\
\hline \multicolumn{5}{|l|}{ The US Sample $(n=474)$} \\
\hline BIC & 6755.99 & 6342.76 & 5946.03 & 5855.20 \\
\hline SSABIC & 6695.69 & 6260.24 & 5841.29 & 5728.24 \\
\hline AIC & 6676.93 & 6234.56 & 5808.71 & 5688.75 \\
\hline Entropy & 0.93 & 0.91 & 0.93 & 0.93 \\
\hline LMR-LRT, $P$ value & $<.001$ & .02 & .005 & .09 \\
\hline BLRT, $P$ value & $<.001$ & $<.001$ & $<.001$ & $<.001$ \\
\hline
\end{tabular}

${ }^{\mathrm{a} B I C}$ : Bayesian Information Criteria.

${ }^{\mathrm{b}}$ SSABIC: sample size adjusted Bayesian Information Criterion.

${ }^{\mathrm{c}}$ AIC: Akaike Information Criterion.

${ }^{\mathrm{d}}$ LMR-LRT: Lo-Mendell-Rubin likelihood ratio test.

${ }^{\text {e}}$ BLRT: bootstrap likelihood ratio test.

The latent profiles of the participants from the United Kingdom are shown in Figure 2. As shown in this figure, the 3 latent groups differed in terms of symptom severity. Specifically, more than half of the participants were assigned to the first group $(315 / 573,55 \%)$ characterized by low mean item scores across all 6 criteria of social media addiction $(<1.34)$, and this group was labeled as low-risk. The profile pattern of the second group $(190 / 573,33.1 \%)$ was relatively more complex than that of the first group. The participants from the second group were more likely to endorse the salience, tolerance, and mood modification criteria, with item mean scores clustered around the midpoint (range 2.62-2.97), but not the remaining 3 criteria (mean item scores $<2.07$ ). The second group was labeled as at-risk because the mean item scores for half of the criteria approached the cutoff (ie, midpoint) for both the monothetic and polythetic schemes. The third group $(68 / 573,11.9 \%)$ had high mean item scores for all the criteria that were above the cutoff for the monothetic and polythetic schemes (>3.18), and this group was labeled as high-risk.

For the US sample, both the 3-class and the 4-class models demonstrated good data fit, but the former model was chosen because its grouping of participants was more interpretable than that of the latter. The 3 latent groups are shown in Figure 3. As revealed in this figure, the profiles of the first 2 groups were highly similar for the UK and the US samples. Specifically, the low-risk group of the US sample $(295 / 474,62.2 \%)$ had low mean item scores across all 6 criteria $(<1.45)$, and the at-risk group $(136 / 474,28.7 \%)$ tended to endorse the same 3 criteria (salience, tolerance, and mood modification; mean item scores ranged from 2.78 to 3.08 ) but not the other 3 (mean item scores $<1.89)$. 
Figure 2. Latent profiles for the 3-class solution for the UK samples.

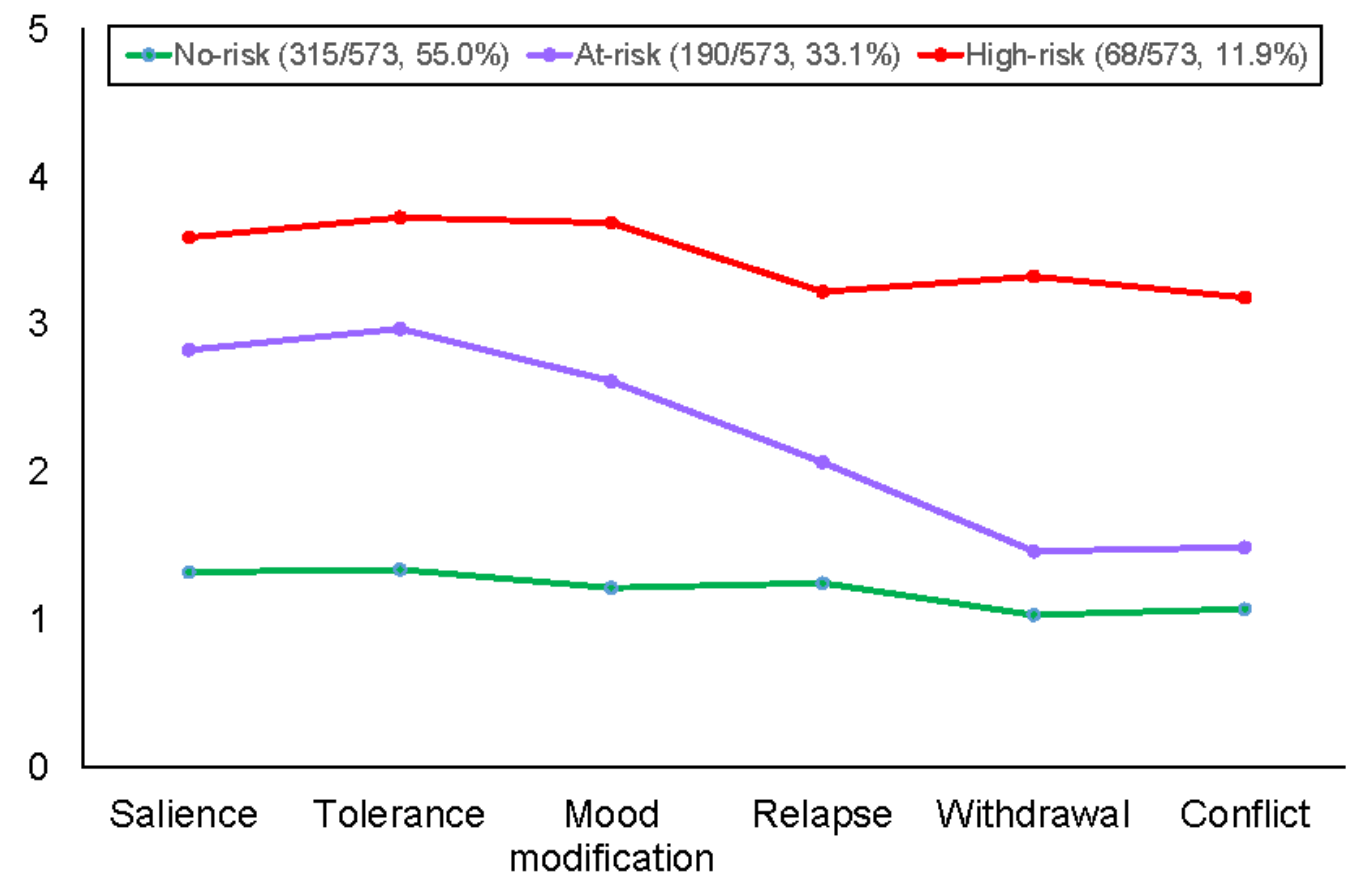

Figure 3. Latent profiles for the 3-class solution for the US samples.

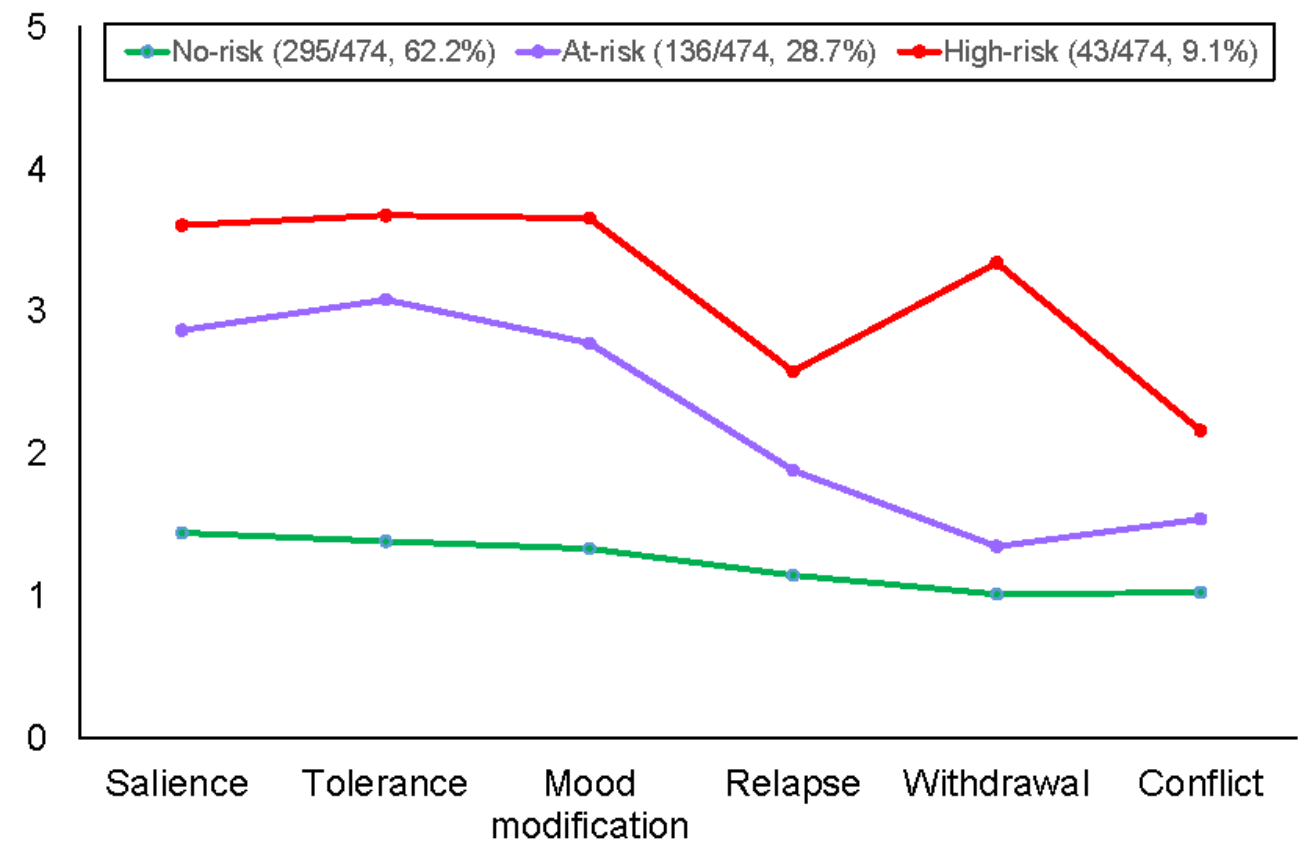

Although the profiles of the low-risk and at-risk groups of participants from the United States were comparable with those of the same 2 groups of the participants from the United Kingdom, the profiles of the third group were different for the 2 samples. Instead of consistently having all scores above the midpoint across all 6 items as their UK counterparts did, the third group of the US sample $(43 / 474,9.1 \%)$ had mean item scores above the midpoint only for two-thirds of the criteria (ie, salience, tolerance, mood modification, and withdrawal; mean item scores>3.34). The third group of the US sample was also labeled as high-risk owing to their members' endorsement of 4 out of 6 criteria that was consistent with the polythetic scheme.

Ad hoc Bonferroni tests were conducted among the 3 latent groups for each of the 6 criteria. The results consistently showed that all the criterion scores of the high-risk group were significantly higher than those of the at-risk group, whose criterion scores were in turn significantly higher than those of the low-risk group $(P<.001)$. These results provided evidence for the distinctness of the profiles of the 3 latent groups. 


\section{Prevalence of Social Media Addiction}

As both of the samples were heterogeneous in terms of demographic characteristics, risk ratios were computed to identify sex and age differences. The results revealed considerable age differences in the prevalence of social media addiction for both samples (Table 3). For the UK sample, younger adults aged between 18 and 34 years were at a 4-fold higher risk of social media addiction than their older counterparts aged between 50 and 65 years, and this pattern of findings was consistent across the various classification schemes. For the US sample, the risk of social media addiction was 2 to 4 times higher in the group of younger adults compared with the group of older adults. However, sex differences in the prevalence of social media addiction were not prominent for both samples, except female participants from the US sample were found to have higher risks of social media addiction than their male counterparts when the strict polythetic scheme was adopted for classification.

Table 3. Prevalence of social media addiction by major classification scheme, sex, and age group for the 2 samples $(\mathrm{N}=1047)$.

\begin{tabular}{|c|c|c|c|c|c|c|c|c|c|c|}
\hline \multirow[t]{2}{*}{ Parameters } & \multicolumn{10}{|c|}{ Classification scheme } \\
\hline & $\begin{array}{l}\text { Strict } \\
\text { monothet- } \\
\text { ic, n (\%) }\end{array}$ & $\begin{array}{l}\text { Strict } \\
\text { monothet- } \\
\text { ic, } \mathrm{RR}^{\mathrm{a}}\end{array}$ & $\begin{array}{l}\text { Strict poly- } \\
\text { thetic, } \mathrm{n} \\
(\%)\end{array}$ & $\begin{array}{l}\text { Strict } \\
\text { polythet- } \\
\text { ic, RR }\end{array}$ & $\begin{array}{l}\text { Monothet- } \\
\text { ic, } \mathrm{n}(\%)\end{array}$ & $\begin{array}{l}\text { Monothet- } \\
\text { ic, RR }\end{array}$ & $\begin{array}{l}\text { Polythetic, } \\
\text { n }(\%)\end{array}$ & $\begin{array}{l}\text { Polythetic, } \\
\text { RR }\end{array}$ & $\begin{array}{l}\text { Latent } \\
\text { profile }^{\mathrm{b}}, \\
\mathrm{n}(\%)\end{array}$ & $\begin{array}{l}\text { Latent } \\
\text { profile }^{\mathrm{b}}, \\
\text { RR }\end{array}$ \\
\hline \multicolumn{11}{|c|}{ The UK Sample (n=573) } \\
\hline Total & $4(0.7)$ & $-^{c}$ & $23(4)$ & - & $29(5.1)$ & - & $86(15)$ & - & $68(11.9)$ & - \\
\hline \multicolumn{11}{|l|}{ Sex } \\
\hline Male & $7(1.2)$ & $\mathrm{N} / \mathrm{A}^{\mathrm{d}}$ & $28(4.9)$ & 1.56 & $35(6.1)$ & 1.58 & $101(17.6)$ & 1.53 & $72(12.6)$ & 1.18 \\
\hline Female & $0(0)$ & $\operatorname{Ref}^{\mathrm{e}}$ & $18(3.1)$ & Ref & $22(3.8)$ & Ref & $66(11.5)$ & Ref & $62(10.8)$ & Ref \\
\hline \multicolumn{11}{|c|}{ Age group (years) } \\
\hline $18-34$ & $12(2.1)$ & 4.03 & $48(8.4)$ & 4.09 & $60(10.5)$ & 4.09 & $144(25.1)$ & 3.78 & $132(23)$ & 6.20 \\
\hline $35-49$ & $0(0)$ & N/A & $17(3)$ & 1.45 & $22(3.8)$ & 1.49 & $90(15.7)$ & 2.36 & $63(11)$ & 2.41 \\
\hline $50-65$ & $3(0.5)$ & Ref & $12(2.1)$ & Ref & $15(2.6)$ & Ref & $38(6.6)$ & Ref & $26(5)$ & Ref \\
\hline \multicolumn{11}{|c|}{ The US sample $(n=474)$} \\
\hline Total & $1(0.2)$ & - & $12(2.5)$ & - & $12(2.5)$ & - & $52(11)$ & - & $43(9.1)$ & - \\
\hline \multicolumn{11}{|l|}{ Sex } \\
\hline Male & $2(0.4)$ & N/A & $21(4.4)$ & 4.38 & $13(2.7)$ & 1.23 & $64(13.5)$ & 1.66 & $47(9.9)$ & 1.25 \\
\hline Female & $0(0)$ & Ref & $4(0.8)$ & Ref & $11(2.3)$ & Ref & $39(8.2)$ & Ref & $39(8)$ & Ref \\
\hline \multicolumn{11}{|c|}{ Age group (years) } \\
\hline $18-34$ & $0(0)$ & N/A & $16(3.4)$ & 2.24 & $20(4.2)$ & 4.19 & $72(15.2)$ & 2.16 & $60(12.7)$ & 2.74 \\
\hline $35-49$ & $3(0.6)$ & N/A & $15(3.2)$ & 2.09 & $15(3.2)$ & 3.13 & $60(12.7)$ & 1.79 & $54(11.4)$ & 1.13 \\
\hline $50-65$ & $0(0)$ & Ref & $7(1.5)$ & Ref & $5(1.1)$ & Ref & $34(7.2)$ & Ref & $24(5.1)$ & Ref \\
\hline
\end{tabular}

${ }^{\mathrm{a}} \mathrm{RR}$ : risk ratio.

${ }^{\mathrm{b}}$ The low-risk and at-risk groups were coded as 0 , and the high-risk group was coded as 1 .

${ }^{\mathrm{c}}$ No reference group.

${ }^{\mathrm{d}}$ N/A: not applicable (cannot be computed).

${ }^{\mathrm{e}} \mathrm{Ref}$ : reference group.

\section{Sensitivity and Specificity Analysis}

The sensitivity and specificity analyses are summarized in Table 4. The various classification schemes generally had a high sensitivity (83\%-100\%) for both the UK and the US samples, with the exception of the polythetic scheme that had somewhat lower sensitivity (74\% and $73 \%$ for the UK and the US samples, respectively). The specificity and negative predictive value were also high across the various schemes (>88\% and >95\%). Moreover, there were considerable consistencies or overlaps $(>88 \%)$ in group membership between the latent profiles and the high-versus-low-risk groups classified by all the schemes, indicating that the participants classified by the various schemes were largely consistent with the latent groups embedded in the data when their sensitivity, specificity, and negative predictive value were examined. 
Table 4. Sensitivity and specificity analyses of various classification schemes with the latent group as the benchmark (N=1047).

\begin{tabular}{|c|c|c|c|c|c|}
\hline \multirow{2}{*}{$\begin{array}{l}\text { Sample and classification } \\
\text { scheme }\end{array}$} & \multicolumn{5}{|c|}{ Indicator of sensitivity and specificity analyses (\%) } \\
\hline & Sensitivity & Specificity & Positive predictive value & Negative predictive value & Overall consistency \\
\hline \multicolumn{6}{|l|}{ The UK sample (n=573) } \\
\hline Strict monothetic & 100 & 89 & 6 & 100 & 89 \\
\hline Strict polythetic & 100 & 92 & 34 & 100 & 92 \\
\hline Monothetic & 100 & 93 & 43 & 100 & 93 \\
\hline Polythetic & 74 & 99 & 94 & 96 & 95 \\
\hline \multicolumn{6}{|l|}{ The US sample (n=474) } \\
\hline Strict monothetic & 100 & 91 & 2 & 100 & 91 \\
\hline Strict polythetic & 83 & 93 & 23 & 100 & 93 \\
\hline Monothetic & 100 & 93 & 28 & 100 & 93 \\
\hline Polythetic & 73 & 99 & 88 & 97 & 96 \\
\hline
\end{tabular}

Despite these similarities among the schemes, it is important to note that the schemes differed vastly in their positive predictive value. Only the polythetic scheme had a high positive predictive value for both samples (>88\%), whereas the other schemes had a low positive predictive value $(<43 \%)$. These results indicated that only the polythetic scheme could identify high-risk participants that were largely consistent with the data, whereas all other schemes might fail to identify a considerable proportion of participants who were classified as high risk by the data-driven LPA.

In summary, the various classification schemes generally had good sensitivity and specificity, but their positive predictive value was low, indicating that those participants who were classified by these schemes as having high risks only represented a relatively small proportion of participants from the data-driven, latent high-risk group. Despite having somewhat lower sensitivity than other schemes, the polythetic scheme had a high positive predictive value, indicating that the membership of various groups derived from the polythetic scheme overlapped with the group membership identified by the data-driven latent profiles as much as $96 \%$ of the time. Taken together, the polythetic scheme yielded the best balance of sensitivity, specificity, positive predictive value, and negative predictive value among the major classification schemes, and may thus be optimal for classifying cases of social media addiction.

\section{Risk Ratio of Mental Health Problems by Classification Scheme and Criteria}

Table 5 presents the descriptive statistics of mental health problems for both low-to-at-risk and high-risk groups classified by various schemes, whereas Table 6 displays the risk ratios of various major mental health problems associated with the incidence of social media addiction at both the scale and item levels. In these analyses, the reference group referred to the low-to-at-risk group classified by various schemes of social media addiction. 
Table 5. Descriptive statistics of mental health problems by case classification of major schemes for the 2 samples $(\mathrm{N}=1047)$.

\begin{tabular}{|c|c|c|c|c|c|c|}
\hline \multirow[t]{2}{*}{ Scheme and mental health problem } & \multicolumn{3}{|c|}{ The UK sample $(n=573)$} & \multicolumn{3}{|c|}{ The US sample $(n=474)$} \\
\hline & $\begin{array}{l}\text { High-risk group, } \\
\text { mean (SD) }\end{array}$ & $\begin{array}{l}\text { Low-to-at-risk } \\
\text { group, mean (SD) }\end{array}$ & $P$ value $^{\mathrm{a}}$ & $\begin{array}{l}\text { High-risk group, } \\
\text { mean (SD) }\end{array}$ & $\begin{array}{l}\text { Low-to-at-risk } \\
\text { group, mean (SD) }\end{array}$ & $P$ value \\
\hline \multicolumn{7}{|l|}{ Strict monothetic } \\
\hline Depression & $41.25(9.64)$ & $16.87(11.08)$ & $<.001$ & $N / A^{b}$ & N/A & N/A \\
\hline Anxiety & $64.25(12.61)$ & $40.07(13.11)$ & $<.001$ & N/A & N/A & N/A \\
\hline \multicolumn{7}{|l|}{ Strict polythetic } \\
\hline Depression & $32.39(11.26)$ & $16.40(10.79)$ & $<.001$ & $26.08(8.62)$ & $16.11(10.89)$ & .002 \\
\hline Anxiety & $56.13(13.88)$ & $39.56(12.80)$ & $<.001$ & $48.25(14.52)$ & $38.39(13.12)$ & .01 \\
\hline \multicolumn{7}{|l|}{ Monothetic } \\
\hline Depression & $27.03(13.30)$ & $16.51(10.88)$ & $<.001$ & $26.00(11.08)$ & $16.12(10.83)$ & .002 \\
\hline Anxiety & $52.90(14.20)$ & $39.55(12.86)$ & $<.001$ & $52.00(11.95)$ & $38.32(13.11)$ & .001 \\
\hline \multicolumn{7}{|l|}{ Polythetic } \\
\hline Depression & $26.02(12.67)$ & $15.47(10.21)$ & $<.001$ & $24.65(10.38)$ & $15.36(10.58)$ & $<.001$ \\
\hline Anxiety & $48.35(13.94)$ & $38.76(12.59)$ & $<.001$ & $45.25(13.09)$ & $37.83(13.04)$ & $<.001$ \\
\hline \multicolumn{7}{|l|}{ Latent profile $^{c}$} \\
\hline Depression & $26.59(12.70)$ & $15.75(10.39)$ & $<.001$ & $24.00(11.02)$ & $15.62(10.65)$ & $<.001$ \\
\hline Anxiety & $50.10(14.01)$ & $38.87(12.56)$ & $<.001$ & $45.98(13.07)$ & $37.91(13.04)$ & $<.001$ \\
\hline
\end{tabular}

${ }^{\text {a }} P$ value indicates the significance level of an independent sample $t$ test (1-tailed) for each mental health problem of a sample.

b/A: not applicable (cannot be computed).

${ }^{\mathrm{c}}$ The low-risk and at-risk groups were coded as 0 , and the high-risk group was coded as 1 . 
Table 6. Risk ratio of mental health problems by classification scheme and criteria for social media addiction (N=1047).

\begin{tabular}{|c|c|c|c|c|}
\hline \multirow[t]{2}{*}{ Parameters } & \multicolumn{2}{|c|}{ Mental health problems in the UK sample $(\mathrm{n}=573), \mathrm{RR}^{\mathrm{a}}$} & \multicolumn{2}{|c|}{ Mental health problems in the US sample $(n=474), R R$} \\
\hline & Probable depression & Probable anxiety & Probable depression & Probable anxiety \\
\hline \multicolumn{5}{|l|}{ Classification scheme $^{b}$} \\
\hline Strict monothetic & $\mathrm{N} / \mathrm{A}^{\mathrm{c}}$ & N/A & N/A & N/A \\
\hline Strict polythetic & 5.99 & 6.17 & 6.59 & 14.81 \\
\hline Monothetic & 2.77 & 8.48 & 3.92 & 2.90 \\
\hline Polythetic & 4.46 & 3.27 & 6.21 & 2.65 \\
\hline Latent profile & 4.17 & 3.85 & 4.60 & 2.79 \\
\hline \multicolumn{5}{|l|}{ Criteria $^{d}$} \\
\hline Salience & 1.97 & 2.18 & 2.51 & 1.68 \\
\hline Tolerance & 2.58 & 2.16 & 3.35 & 2.08 \\
\hline Mood modification & 4.34 & 3.54 & 6.33 & 2.99 \\
\hline Loss of control & 1.57 & 1.38 & 2.62 & 2.29 \\
\hline Withdrawal & 5.99 & 3.52 & 7.29 & 8.95 \\
\hline Conflict & 7.02 & 2.79 & 3.88 & 4.33 \\
\hline \multicolumn{5}{|l|}{ Criteria $^{\mathrm{e}}$} \\
\hline Salience & 1.44 & 1.67 & 2.19 & 1.66 \\
\hline Tolerance & 1.29 & 1.63 & 2.82 & 1.81 \\
\hline Mood modification & 3.93 & 2.83 & 5.22 & 3.20 \\
\hline Loss of control & 2.37 & 1.87 & 3.06 & 3.09 \\
\hline Withdrawal & 3.17 & 3.54 & 4.60 & 2.79 \\
\hline Conflict & 4.08 & 3.79 & 3.30 & 2.65 \\
\hline
\end{tabular}

${ }^{\mathrm{a}} \mathrm{RR}$ : risk ratio, with the low-risk and at-risk groups coded as 0 , and the high-risk group was coded as 1.

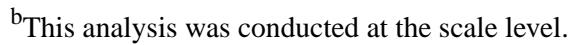

${ }^{\mathrm{c}} \mathrm{N} / \mathrm{A}$ : not applicable (cannot be computed).

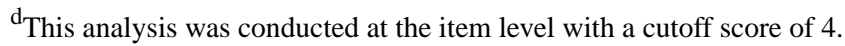

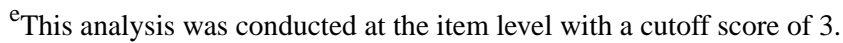

For the UK sample, the risk of probable depression or anxiety was about 3 to 8 times higher in the high-risk group by various schemes than in the low-to-at-risk group. Similarly, for the US sample, the risk of having any of these mental health problems was about 3 to 15 times higher for the high-risk (vs no-to-low-risk) group identified by various schemes.

As the profiles of the latent groups revealed some interesting patterns across the 6 criteria for social media addiction, additional analyses were conducted at the item (criterion) level. Specifically, each of the BSMAS items was dummy coded according to the cutoff adopted in the strict monothetic and strict polythetic schemes (ie, 4 out of a 5-point scale). As shown in the middle panel of Table 6 , the risk of probable depression or anxiety was about 3 to 9 times higher for the mood modification, withdrawal, and conflict criteria for both the UK and the US samples when a high cutoff of 4 was applied.

The BSMAS items were also dummy coded according to the cutoff adopted in the monothetic and the polythetic schemes (ie, 3 out of a 5-point scale), and the results are summarized in the lower panel of Table 6 . Similar to the findings derived from

a higher cutoff of 4 , the risk of probable depression or anxiety was about 3 to 5 times higher for the mood modification, withdrawal, and conflict criteria for both the UK and the US samples.

\section{Discussion}

\section{Principal Findings}

Social media addiction has emerged as a prevalent problem of public concern in the modern cyber era, and this emergent problem has been examined in the context of the COVID-19 pandemic. Although the prevalence rates of social media addiction for both samples obtained in this period are comparable with those derived from the same countries before the pandemic [61], the psychiatric problems reported by both samples are more prevalent than those reported in previous studies [62]. These findings indicate that the residents of the United Kingdom and the United States could be emotionally overwhelmed by enormous stressors elicited during the early 
phase of the pandemic $[62,63]$, but the prevalence of social media addiction remained largely stable at that stage.

This study is the first to adopt a nuanced analysis of the various schemes that have been widely used for case classification purposes. Our findings indicate that the application of diverse schemes yields varied prevalence estimates, and testing these schemes against the data-driven, latent profile analytic approach thus generates valuable information that unveils the relative performance of different schemes in case classification.

In our study, three latent profiles are found to be embedded in the data: low-risk, at-risk, and high-risk. It is noteworthy that the shape of the symptom profile of the at-risk group was distinct from that of the other 2 groups. For the at-risk group, the endorsement of half of the criteria (ie, salience, tolerance, and mood modification) tended to be more similar to the endorsement of those by the high-risk group, whereas the endorsement of the other half (ie, loss of control, withdrawal, and conflict) by the at-risk group tended to be more similar to the endorsement of those by the low-risk group. These findings show that a dichotomous (low-risk vs high-risk) classification scheme may be inadequate. Instead, a tripartite classification scheme may be more appropriate for capturing respondents' distinct symptom characteristics of social media addiction, especially for the at-risk group whose symptom profile is similar to the low-risk and high-risk groups in certain criteria but not others.

In general, most classification schemes used in existing studies have good sensitivity and specificity when compared with the latent groups identified in our latent profile analyses. However, a low positive predictive value is found in most of the schemes, with the exception of the polythetic scheme. The present findings indicate that both strict monothetic and monothetic schemes have perfect sensitivity $(100 \%)$ but at the cost of low positive predictive values (2\%-43\%). These 2 schemes may be too conservative, such that a large proportion of individuals with probable social media addiction are excluded from further assessment or follow-ups. In contrast, despite having slightly lower sensitivity than the other schemes, the polythetic scheme appears to have a more balanced performance across all psychometric indicators.

\section{Research and Practical Implications}

These new findings have research and practical implications. Specifically, the study delineates the strengths and weaknesses of each classification scheme, thus guiding decisions for selecting an optimal scheme for making population-level estimates of social media addiction. The findings indicate that the various major classification schemes have a large degree of heterogeneity, both in terms of estimating the prevalence rates of social media addiction as well as screening and detecting cases of social media addiction. With regard to prevalence estimates, researchers utilizing strict classification schemes may tend to obtain very low prevalence rates of social media addiction. As shown in this study, such discrepancies can be as large as $10 \%$ to $15 \%$ (eg, using polythetic vs strict monothetic schemes). It is noteworthy that the polythetic scheme was found to have relatively high consistency with the benchmark data of the 2 independent samples, with discrepancies of only $2 \%$ to
$3 \%$ (11\% vs $9 \%$ in the United States; $15 \%$ vs $12 \%$ in the United Kingdom). Thus, the present findings provide some empirical evidence that polythetic classification may best reflect classifications identified using a data-driven approach and is optimal when the goal is to identify a broad group of individuals at risk for social media addiction.

Furthermore, the assessment of social media addiction has become an issue of growing importance for mental health professionals, with some countries formulating public health policies and providing extensive training to guide professionals in distinguishing clients with varying severity levels of the problem [64]. As precise case classification is crucial for appropriate referral to tailored intervention, a better understanding of how well a screening instrument function using different scoring methods becomes important. In evaluating screening tools, the sensitivity and specificity of classification schemes have traditionally been emphasized. However, basing classification schemes solely on these 2 indices is insufficient for making clinical decisions at the individual level and may even be misleading in some cases [65]. This is because both indicators of sensitivity and specificity are population-based indices that represent properties of the screening test in itself [66], but the 2 predictive values further include sample-relevant information, such as the base rate of a given problem area [67]. Therefore, the use of multiple indices, including positive and negative predictive values, is a notable strength of our analyses, providing valuable data that could inform the scoring and interpretation of the BSMAS within the context of clinical assessment $[65,68]$.

The BSMAS is a brief measure that has been commonly adopted to assess symptoms of social media addiction, although our results highlight several considerations relevant to clinicians' choice of classification schemes. Despite demonstrating high sensitivity and specificity, the use of the strict monothetic, strict polythetic, and monothetic schemes are found to be more prone to missing members of the high-risk group derived from the actual data (ie, positive predictive values ranging from $2 \%$ to $43 \%$ ) as compared with the polythetic scheme (ie, positive predictive values of $88 \%$ and $94 \%$ ). These findings demonstrate that the polythetic scheme has superior positive predictive rates of social media addiction compared with the other schemes, indicating the greater utility of the polythetic scheme in detecting individuals who are at high risk for social media addiction.

The polythetic scheme as compared with the monothetic scheme is more consistent with the current theoretical approaches to psychological functioning and mental health, as the polythetic scheme emphasizes a prototypical perspective (ie, requiring the presence of many rather than all symptoms) rather than a classical, monothetic perspective (ie, requiring the presence of all symptoms) to mental health [69]. Characterized by a prototypical approach, the polythetic scheme does not necessitate the presence of all symptoms within a problem area, representing an approach that is more attuned toward individual variability and heterogeneity, both of which are frequently observed in clinical and research settings. Similar to many other problem domains, the present findings indicate that social media addiction may be conceptualized as a continuum ranging from no to high risks, with a considerable proportion of at-risk 
individuals clustered somewhere between the 2 extremes. Hence, the polythetic classification scheme is more similar to current assessment approaches to mental health problems, such as the DSM-5 and the 11th version of the International Statistical Classification of Diseases and Related Health Problems (ICD-11) [27,70]

Although information technology addiction (eg, social media addiction and gaming disorder) is currently not a diagnosable condition in the DSM-5 [71], a recent expert review has outlined meta-level criteria for determining whether different behavioral addictions may warrant the designation of other specified disorders due to addictive behaviors under the ICD-11 [72]. To determine whether social media addiction is present based on specific symptoms, this study fills the knowledge gap by revealing 3 symptoms of social media addiction with high-risk ratios with comorbid problems of depression and anxiety: mood modification, withdrawal, and conflict (Table 6). The replicable findings across the 2 independent samples suggest that these symptoms are crucial for the assessment of social media addiction. More importantly, these findings echo the classifications of a related problem of gaming disorder and other behavioral disorders in the ICD-11, in which conflict and adverse consequences in significant life domains are essential for a diagnosis.

This study further reveals that individuals identified with social media addiction have a high risk of probable depression and anxiety. Primarily, these findings indicate that the classification schemes of social media addiction may serve as a risk indicator in the screening process for potentially detecting comorbid problems with depression and anxiety. More importantly, several specific symptoms of social media addiction tend to have stronger connections with depression and anxiety, including mood modification, withdrawal, and conflict. Our item-level analyses identified several associations that warrant future research and attention by clinicians. First, the association between the specific symptoms of conflict and depression and anxiety corroborates those that have been empirically unveiled in a variety of contexts [73,74], highlighting conflict arising from social media addiction as a potential pathway linked with both mental health conditions. Clinicians may need to evaluate how conflict arising from social media addiction is related to depressive symptoms, such as the feelings of letting oneself and their significant others down, feelings of worthlessness, or anxiety symptoms associated with the monitoring of worry and rumination thoughts that are attributable to addictive use of social media [75,76]. Second, mood modification through addictive use of social media to avoid facing real-life problems is associated with a high risk of probable depression and anxiety. This finding may reflect individuals who use social media as a refuge to evade real-life challenges, duties, or responsibilities. If this is the case, clinicians may need to address social media addiction as a maladaptive, avoidant coping response that likely serves as a maintaining factor for both depression and anxiety $[77,78]$. Finally, as withdrawal symptoms are associated with psychological distress, individuals who are at risk for social media addiction may benefit from developing alternative coping skills that can replace social media activities when experiencing withdrawal.
In addition to the use of the BSMAS as a diagnostic tool for identifying individuals with social media addiction for treatment referral, this screening tool can also serve as an effective tool for early screening of at-risk cases to prevent further development into social media addiction. As prevention is often more cost-effective than treatment [79], broad-based screening can be valuable when mental health intervention resources are available in the community to serve the identified at-risk individuals. Given that this study evaluates the performance of multiple classification schemes against the empirically-derived benchmark, the findings can provide useful guidance for health care professionals to select the scheme most appropriate for their intervention schemes.

\section{Research Limitations and Directions}

Before concluding, caution should be exercised. First, this study adopted a quantitative design that included only validated measures with structured close-ended questions. The present inquiry thus focused on the typical symptoms of social media addiction, anxiety, and depression. The widely adopted quantitative design should be supplemented with qualitative data collection methods, such as narrative interviews and focus groups, which can broaden the scope of inquiry by unveiling participants' unique experiences [80,81]. Thus, a mixed methods design is encouraged to combine quantitative and qualitative methods to gain a more comprehensive perspective on social media addiction.

Second, our study used a web-based survey method for data collection and is thus vulnerable to the shortcomings inherent in this type of method. Although the screening function of the web-based survey platform allows the recruitment of the present samples whose demographic profiles resemble those of their respective populations, it is important to reiterate that nonprobabilistic sampling method was used in participant recruitment. Participants signed up for the web-based survey voluntarily upon placing an advertisement on the website, and such self-selection could potentially elicit sample bias.

Third, our study adopted a symptom approach in the examination of social media addiction and its mental health implications. Validated measures assessing a standard set of symptoms of social media addiction and the 2 psychiatric problems were administered. It is noteworthy that we did not include any measures of time for overall internet use or social media engagement $[82,83]$; thus, the amount and pattern of social media use were not assessed. For criterion assessment, only anxiety and depression were measured because both are major psychiatric comorbidities of information technology addiction [84,85]. Apart from psychiatric problems, individuals with information technology addiction also experience disruptions in other life domains, such as interpersonal relations and job performance $[86,87]$. The scope of daily life dysfunction should be broadened by including a greater variety of life domains for a more comprehensive evaluation of daily life challenges experienced by individuals with social media addiction.

Fourth, it is noteworthy that this study was conducted during the COVID-19 pandemic. As the massive global transmission of this unknown virus was unprecedented, an avalanche of false 
and misleading information was disseminated through social media. Frequent use of social media was associated with COVID-19 anxiety that disturbed sleep quality $[88,89]$. Such psychological responses may not be fully captured by the traditional measures of mental health. Future research may consider using measures that capture COVID-19-specific stressors and experiences, such as loss of family and friends because of COVID-19 or exposure to misinformation about the pandemic via social media use [90].

Finally, although efforts have been made to replicate the findings in 2 independent samples from English-speaking countries with high internet penetration rates [50], the present findings cannot be generalized to individuals from other countries or cultural backgrounds. This is particularly the case as multinational meta-analyses have revealed the prevalence of information technology addiction and its differential underlying psychological mechanisms across cultural regions [61,84]. Therefore, future research should be expanded to include more countries with varying levels of cultural individualism and internet penetration. Data derived from a myriad of countries with diverse backgrounds enable researchers to make cross-cultural comparisons at both the individual and country levels [91].

\section{Conclusions}

In conclusion, this study evaluated 4 major schemes widely adopted to classify cases of social media addiction. Using latent profiles identified from empirical data as a benchmark, the performance of the polythetic scheme is more well-balanced in attaining relatively high levels of sensitivity, specificity, positive predictive value, and negative predictive value compared with those of the other 3 schemes. Although these findings are largely replicable in the 2 independent samples, efforts should be made to expand the scope of inquiry in countries with diverse cultural backgrounds using a wider range of criterion variables through qualitative methods, thus enriching the discussion and informing future decisions about the potential inclusion of social media addiction in the future versions of the DSM or ICD.

\section{Acknowledgments}

This study was funded by the General Research Fund administered by the Research Grants Council of Hong Kong (grant 17400714). The authors would like to thank Sylvia Lam, Sophie Lau, Janice Leung, and Olivia Qiu for their research and clerical assistance.

\section{Conflicts of Interest}

None declared.

\section{References}

1. Kim H. Enacted social support on social media and subjective well-being. Int J Commun 2014;8:21.

2. Ellison N, Steinfield C, Lampe C. The benefits of Facebook "friends": social capital and college students' use of online social network sites. J Comput Mediat Commun 2007 Jul 1;12(4):1143-1168. [doi: 10.1111/j.1083-6101.2007.00367.x]

3. Cheng C, Wang H, Sigerson L, Chau C. Do the socially rich get richer? A nuanced perspective on social network site use and online social capital accrual. Psychol Bull 2019 Jul;145(7):734-764. [doi: 10.1037/bul0000198] [Medline: 31094537]

4. Rae JR, Lonborg SD. Do motivations for using Facebook moderate the association between Facebook use and psychological well-being? Front Psychol 2015 Jun 12;6:771 [FREE Full text] [doi: 10.3389/fpsyg.2015.00771] [Medline: 26124733]

5. Cheng C, Lau Y, Luk JW. Social capital-accrual, escape-from-self, and time-displacement effects of internet use during the COVID-19 stay-at-home period: prospective, quantitative survey study. J Med Internet Res 2020 Dec 24;22(12):e22740 [FREE Full text] [doi: 10.2196/22740] [Medline: 33320824]

6. Norbury A, Liu SH, Campaña-Montes JJ, Romero-Medrano L, Barrigón ML, Smith E, MEmind Study Group, et al. Social media and smartphone app use predicts maintenance of physical activity during Covid-19 enforced isolation in psychiatric outpatients. Mol Psychiatry 2021 Aug 14;26(8):3920-3930 [FREE Full text] [doi: 10.1038/s41380-020-00963-5] [Medline: $\underline{33318619]}$

7. Ridout B, Campbell A. The use of social networking sites in mental health interventions for young people: systematic review. J Med Internet Res 2018 Dec 18;20(12):e12244 [FREE Full text] [doi: 10.2196/12244] [Medline: $\underline{30563811]}$

8. Kardefelt-Winther D. A conceptual and methodological critique of internet addiction research: towards a model of compensatory internet use. Comput Human Behav 2014 Feb;31:351-354. [doi: 10.1016/j.chb.2013.10.059]

9. Ryan T, Chester A, Reece J, Xenos S. The uses and abuses of Facebook: a review of Facebook addiction. J Behav Addict 2014 Sep;3(3):133-148 [FREE Full text] [doi: 10.1556/JBA.3.2014.016] [Medline: 25317337]

10. Schou Andreassen C, Billieux J, Griffiths MD, Kuss DJ, Demetrovics Z, Mazzoni E, et al. The relationship between addictive use of social media and video games and symptoms of psychiatric disorders: a large-scale cross-sectional study. Psychol Addict Behav 2016 Mar;30(2):252-262. [doi: 10.1037/adb0000160] [Medline: 26999354]

11. Gil-Or O, Levi-Belz Y, Turel O. The "Facebook-self": characteristics and psychological predictors of false self-presentation on Facebook. Front Psychol 2015 Feb 17;6:99 [FREE Full text] [doi: 10.3389/fpsyg. 2015.00099] [Medline: 25741299]

12. Kuss DJ, Griffiths MD. Online social networking and addiction--a review of the psychological literature. Int J Environ Res Public Health 2011 Sep;8(9):3528-3552 [FREE Full text] [doi: 10.3390/ijerph8093528] [Medline: 22016701]

13. Pelling EL, White KM. The theory of planned behavior applied to young people's use of social networking web sites. Cyberpsychol Behav 2009 Dec;12(6):755-759. [doi: 10.1089/cpb.2009.0109] [Medline: 19788377] 
14. Andreassen CS. Online social network site addiction: a comprehensive review. Curr Addict Rep 2015 Jun 01;2(2):175-184. [doi: $10.1007 / \mathrm{s} 40429-015-0056-9]$

15. Kuss D, Griffiths M. Social networking sites and addiction: ten lessons learned. Int J Environ Res Public Health 2017 Mar 17;14(3):311 [FREE Full text] [doi: 10.3390/ijerph14030311] [Medline: 28304359]

16. Griffiths M. A ‘components' model of addiction within a biopsychosocial framework. J Substance Use 2005 Jul 12;10(4):191-197. [doi: 10.1080/14659890500114359]

17. Guze S. Diagnostic and statistical manual of mental disorders, 4th edition (DSM-IV). AJP 1995 Aug;152(8):1228. [doi: 10.1176/ajp.152.8.1228]

18. Elphinston RA, Noller P. Time to face it! Facebook intrusion and the implications for romantic jealousy and relationship satisfaction. Cyberpsychol Behav Soc Netw 2011 Nov;14(11):631-635. [doi: 10.1089/cyber.2010.0318] [Medline: 21548798]

19. Andreassen CS, Pallesen S, Griffiths MD. The relationship between addictive use of social media, narcissism, and self-esteem: findings from a large national survey. Addict Behav 2017 Jan;64:287-293. [doi: 10.1016/j.addbeh.2016.03.006] [Medline: 27072491]

20. Marino C, Vieno A, Altoè G, Spada MM. Factorial validity of the Problematic Facebook Use Scale for adolescents and young adults. J Behav Addict 2017 Mar 01;6(1):5-10 [FREE Full text] [doi: 10.1556/2006.6.2017.004] [Medline: 28198639]

21. Caplan S. Theory and measurement of generalized problematic internet use: a two-step approach. Comput Human Behav 2010 Sep;26(5):1089-1097. [doi: 10.1016/j.chb.2010.03.012]

22. van den Eijnden RJ, Lemmens JS, Valkenburg PM. The social media disorder scale. Comput Human Behav 2016 Aug;61:478-487. [doi: 10.1016/j.chb.2016.03.038]

23. Sahin C. Social media addiction scale-student form: the reliability and validity study. Turk Online J Educ Technol 2018 Jan;17(1):169-182.

24. Andreassen CS, Torsheim T, Brunborg GS, Pallesen S. Development of a Facebook addiction scale. Psychol Rep 2012 Apr;110(2):501-517. [doi: 10.2466/02.09.18.PR0.110.2.501-517] [Medline: 22662404]

25. Wang H, Sigerson L, Cheng C. Digital nativity and information technology addiction: age cohort versus individual difference approaches. Comput Human Behav 2019 Jan;90:1-9. [doi: 10.1016/j.chb.2018.08.031]

26. Kendell R. Diagnostic and statistical manual of mental disorders, 3rd edition. Am J Psychiatry 1988 Oct;145(10):1301-1302 [FREE Full text] [doi: 10.1176/ajp.145.10.1301]

27. American Psychiatric Association. Diagnostic and Statistical Manual of Mental Disorders (DSM-5®). Washington, DC: American Psychiatric Publishing; 2013.

28. Brown R. Gaming, gambling and other addictive play. In: Adult Play. Amsterdam, the Netherlands: Swets and Zillinger; 1991.

29. Pontes HM, Taylor M, Stavropoulos V. Beyond "Facebook Addiction": the role of cognitive-related factors and psychiatric distress in social networking site addiction. Cyberpsychol Behav Soc Netw 2018 Apr;21(4):240-247. [doi: 10.1089/cyber.2017.0609] [Medline: 29589972]

30. Alaika O, Doghmi N, Cherti M. Social media addiction among Moroccan university students: a cross sectional survey. PAMJ-OH 2020 Apr 3;1:4. [doi: 10.11604/pamj-oh.2020.1.4.21930]

31. Mamun MA, Griffiths MD. The association between Facebook addiction and depression: a pilot survey study among Bangladeshi students. Psychiatry Res 2019 Jan;271:628-633. [doi: 10.1016/j.psychres.2018.12.039] [Medline: 30791335]

32. Azizi SM, Soroush A, Khatony A. The relationship between social networking addiction and academic performance in Iranian students of medical sciences: a cross-sectional study. BMC Psychol 2019 May 03;7(1):28 [FREE Full text] [doi: 10.1186/s40359-019-0305-0] [Medline: $\underline{31053171]}$

33. Brailovskaia J, Schillack H, Margraf J. Facebook addiction disorder in Germany. Cyberpsychol Behav Soc Netw 2018 Jul;21(7):450-456. [doi: 10.1089/cyber.2018.0140] [Medline: 29995531]

34. Tang CS, Koh YY. Online social networking addiction among college students in Singapore: comorbidity with behavioral addiction and affective disorder. Asian J Psychiatr 2017 Feb;25:175-178. [doi: 10.1016/j.ajp.2016.10.027] [Medline: 28262144]

35. Bujang MA, Adnan TH. Requirements for minimum sample size for sensitivity and specificity analysis. J Clin Diagn Res 2016 Oct;10(10):YE01-YE06 [FREE Full text] [doi: 10.7860/JCDR/2016/18129.8744] [Medline: 27891446]

36. Oberski D. Mixture models: latent profile and latent class analysis. In: Modern Statistical Methods for HCI. Cham: Springer; 2016.

37. Collins L, Lanza S. Latent Class and Latent Transition Analysis: With Applications in the Social, Behavioral, and Health Sciences. Hoboken, NJ: John Wiley and Sons; 2009.

38. Williams G, Kibowski F. Latent class analysis and latent profile analysis. In: Handbook of Methodological Approaches to Community-Based Research: Qualitative, Quantitative, and Mixed Methods. New York, NY: Oxford University Press; 2016.

39. Bányai F, Zsila A, Király O, Maraz A, Elekes Z, Griffiths MD, et al. Problematic social media use: results from a large-scale nationally representative adolescent sample. PLoS One 2017 Jan 9;12(1):e0169839 [FREE Full text] [doi:

10.1371/journal.pone.0169839] [Medline: 28068404] 
40. Robinson A, Bonnette A, Howard K, Ceballos N, Dailey S, Lu Y, et al. Social comparisons, social media addiction, and social interaction: an examination of specific social media behaviors related to major depressive disorder in a millennial population. J Appl Behav Res 2019 Jan 08;24(1):e12158. [doi: 10.1111/jabr.12158]

41. Keles B, McCrae N, Grealish A. A systematic review: the influence of social media on depression, anxiety and psychological distress in adolescents. Int J Adol Youth 2019 Mar 21;25(1):79-93. [doi: 10.1080/02673843.2019.1590851]

42. Primack BA, Karim SA, Shensa A, Bowman N, Knight J, Sidani JE. Positive and negative experiences on social media and perceived social isolation. Am J Health Promot 2019 Jul;33(6):859-868. [doi: 10.1177/0890117118824196] [Medline: 30661371]

43. Feinstein BA, Bhatia V, Hershenberg R, Davila J. Another venue for problematic interpersonal behavior: the effects of depressive and anxious symptoms on social networking experiences. J Soc Clin Psychol 2012 Apr;31(4):356-382. [doi: 10.1521/jscp.2012.31.4.356]

44. Rosenthal SR, Buka SL, Marshall BD, Carey KB, Clark MA. Negative experiences on Facebook and depressive symptoms among young adults. J Adolesc Health 2016 Nov;59(5):510-516. [doi: 10.1016/j.jadohealth.2016.06.023] [Medline: 27546886]

45. Sigerson L, Li AY, Cheung MW, Cheng C. Examining common information technology addictions and their relationships with non-technology-related addictions. Comput Human Behav 2017 Oct;75:520-526. [doi: 10.1016/j.chb.2017.05.041]

46. Ruggieri S, Santoro G, Pace U, Passanisi A, Schimmenti A. Problematic Facebook use and anxiety concerning use of social media in mothers and their offspring: an actor-partner interdependence model. Addict Behav Rep 2020 Jun;11:100256 [FREE Full text] [doi: 10.1016/j.abrep.2020.100256] [Medline: 32467845]

47. Lee-Won RJ, Herzog L, Park SG. Hooked on Facebook: the role of social anxiety and need for social assurance in problematic use of Facebook. Cyberpsychol Behav Soc Netw 2015 Oct;18(10):567-574. [doi: 10.1089/cyber.2015.0002] [Medline: 26383178]

48. Casale S, Fioravanti G. Satisfying needs through Social Networking Sites: a pathway towards problematic internet use for socially anxious people? Addict Behav Rep 2015 Jun;1:34-39 [FREE Full text] [doi: 10.1016/j.abrep.2015.03.008] [Medline: 29531977]

49. Peer E, Brandimarte L, Samat S, Acquisti A. Beyond the Turk: alternative platforms for crowdsourcing behavioral research. J Experimental Soc Psychol 2017 May;70:153-163. [doi: 10.1016/j.jesp.2017.01.006]

50. World internet usage and population statistics 2020 year-Q3 estimates. Internet World Stats. URL: https://www. internetworldstats.com/stats.htm [accessed 2020-12-09]

51. Cheng C, Jose PE, Sheldon KM, Singelis TM, Cheung MW, Tiliouine H, et al. Sociocultural differences in self-construal and subjective well-being: a test of four cultural models. J Cross Cult Psychol 2011 Jul 1;42(5):832-855. [doi: $10.1177 / 0022022110381117]$

52. Wang H, Cheng C. Psychometric evaluation and comparison of two gaming disorder measures derived from the DSM-5 and ICD-11 frameworks. Front Psychiatry 2020 Dec 17;11:577366 [FREE Full text] [doi: 10.3389/fpsyt.2020.577366] [Medline: 33391047]

53. Shensa A, Escobar-Viera CG, Sidani JE, Bowman ND, Marshal MP, Primack BA. Problematic social media use and depressive symptoms among U.S. young adults: a nationally-representative study. Soc Sci Med 2017 Jun;182:150-157 [FREE Full text] [doi: 10.1016/j.socscimed.2017.03.061] [Medline: 28446367]

54. Pontes HM. Investigating the differential effects of social networking site addiction and internet gaming disorder on psychological health. J Behav Addict 2017 Dec 01;6(4):601-610 [FREE Full text] [doi: 10.1556/2006.6.2017.075] [Medline: 29130329]

55. Radloff LS. The CES-D Scale: a self-report depression scale for research in the general population. Applied Psychol Measurement 1977 Jun 01;1(3):385-401. [doi: 10.1177/014662167700100306]

56. Spielberger C. Manual for the State-Trait Anxiety Inventory (Form Y). Palo Alto, CA: Consulting Psychologists; 1983.

57. Ekkekakis P, Zenko Z. Measurement of affective responses to exercise: from "affectless arousal" to "the most well-characterized" relationship between the body and affect. In: Emotion Measurement. Cambridge, MA: Woodhead; 2016.

58. Ferguson SL, G. Moore EW, Hull DM. Finding latent groups in observed data: a primer on latent profile analysis in Mplus for applied researchers. Int J Behav Develop 2019 Nov 22;44(5):458-468. [doi: 10.1177/0165025419881721]

59. Tein J, Coxe S, Cham H. Statistical power to detect the correct number of classes in latent profile analysis. Struct Equ Modeling 2013 Oct 01;20(4):640-657 [FREE Full text] [doi: 10.1080/10705511.2013.824781] [Medline: 24489457]

60. Trevethan R. Sensitivity, specificity, and predictive values: foundations, pliabilities, and pitfalls in research and practice. Front Public Health 2017 Nov 20;5:307 [FRE Full text] [doi: 10.3389/fpubh.2017.00307] [Medline: 29209603]

61. Cheng C, Lau Y, Chan L, Luk JW. Prevalence of social media addiction across 32 nations: meta-analysis with subgroup analysis of classification schemes and cultural values. Addict Behav 2021 Jun;117:106845 [FREE Full text] [doi: 10.1016/j.addbeh.2021.106845] [Medline: $\underline{33550200]}$

62. Ettman CK, Abdalla SM, Cohen GH, Sampson L, Vivier PM, Galea S. Prevalence of depression symptoms in US adults before and during the COVID-19 pandemic. JAMA Netw Open 2020 Sep 01;3(9):e2019686 [FREE Full text] [doi: 10.1001/jamanetworkopen.2020.19686] [Medline: $\underline{32876685}$ ] 
63. O'Connor RC, Wetherall K, Cleare S, McClelland H, Melson AJ, Niedzwiedz CL, et al. Mental health and well-being during the COVID-19 pandemic: longitudinal analyses of adults in the UK COVID-19 Mental Health and Wellbeing study. Br J Psychiatry 2020 Oct 21;218:326-333 [FREE Full text] [doi: 10.1192/bjp.2020.212] [Medline: 33081860]

64. Cho C. South Korea's efforts to prevent Internet addiction. In: Cambridge Handbook of International Prevention Science. Cambridge, UK: Cambridge University; 2016.

65. Landau S, Milich R, Widiger TA. Predictive power methods may be more helpful for making a diagnosis than sensitivity and specificity. J Child Adolesc Psychopharmacol 1991;1(5):343-351. [doi: 10.1089/cap.1991.1.343] [Medline: 19630684]

66. Streiner DL. Diagnosing tests: using and misusing diagnostic and screening tests. J Pers Assess 2003 Dec;81(3):209-219. [doi: 10.1207/S15327752JPA8103 03] [Medline: 14638445]

67. Petscher Y, Kim Y, Foorman BR. The importance of predictive power in early screening assessments: implications for placement in the response to intervention framework. Assess Eff Interv 2011 Jun;36(3):158-166 [FREE Full text] [doi: 10.1177/1534508410396698] [Medline: 26346970]

68. Ghali H, Ghammem R, Zammit N, Fredj S, Ammari F, Maatoug J, et al. Validation of the Arabic version of the Bergen Facebook addiction scale in Tunisian adolescents. Int J Adolesc Med Health 2019 Sep 24 (forthcoming). [doi: 10.1515/ijamh-2019-0077] [Medline: 31550234]

69. Cantor N, Genero N. Psychiatric diagnosisnatural categorization: A close analogy. In: Contemporary Directions in Psychopathology: Toward the DSM-IV. New York, NY: Guilford; 1986.

70. International Statistical Classification of Diseases and Related Health Problems. 11th edition. World Health Organization. URL: https://www.who.int/standards/classifications/classification-of-diseases [accessed 2021-12-13]

71. Petry NM, Rehbein F, Gentile DA, Lemmens JS, Rumpf H, Mößle T, et al. An international consensus for assessing internet gaming disorder using the new DSM-5 approach. Addiction 2014 Sep;109(9):1399-1406. [doi: 10.1111/add.12457] [Medline: 24456155]

72. Brand M, Rumpf H, Demetrovics Z, Müller A, Stark R, King D, et al. Which conditions should be considered as disorders in the International Classification of Diseases (ICD-11) designation of "other specified disorders due to addictive behaviors"? J Behav Addict 2020 Jun 30 (forthcoming). [doi: 10.1556/2006.2020.00035] [Medline: 32634114]

73. Choi H, Marks NF. Marital conflict, depressive symptoms, and functional impairment. J Marriage Fam 2008;70(2):377-390 [FREE Full text] [doi: 10.1111/j.1741-3737.2008.00488.x] [Medline: 18698378]

74. Sheeber L, Hops H, Alpert A, Davis B, Andrews J. Family support and conflict: prospective relations to adolescent depression. J Abnorm Child Psychol 1997 Aug;25(4):333-344. [doi: 10.1023/a:1025768504415] [Medline: 9304449]

75. Cheng C, Hui W, Lam S. Psychosocial factors and perceived severity of functional dyspeptic symptoms: a psychosocial interactionist model. Psychosom Med 2004;66(1):85-91. [doi: 10.1097/01.psy.0000106885.40753.c1] [Medline: 14747642]

76. Ryum T, Kennair LE, Hjemdal O, Hagen R, Halvorsen J, Solem S. Worry and metacognitions as predictors of anxiety symptoms: a prospective study. Front Psychol 2017 May 31;8:924 [FREE Full text] [doi: 10.3389/fpsyg.2017.00924] [Medline: 28620338]

77. Barlow DH. Anxiety and Its Disorders: The Nature and Treatment of Anxiety and Panic. 2nd edition. New York, NY: Guilford; 2004.

78. Ottenbreit ND, Dobson KS. Avoidance and depression: the construction of the Cognitive-Behavioral Avoidance Scale. Behav Res Ther 2004 Mar;42(3):293-313. [doi: 10.1016/s0005-7967(03)00140-2]

79. Maciosek MV, Coffield AB, Edwards NM, Flottemesch TJ, Goodman MJ, Solberg LI. Priorities among effective clinical preventive services: results of a systematic review and analysis. Am J Prev Med 2006 Jul;31(1):52-61. [doi:

10.1016/j.amepre.2006.03.012] [Medline: 16777543]

80. Adhabi EA, Anozie CB. Literature review for the type of interview in qualitative research. Int J Educ 2017 Sep 20;9(3):86-97. [doi: 10.5296/ije.v9i3.11483]

81. Willis R. The use of composite narratives to present interview findings. Qual Res 2018 Jul 20;19(4):471-480. [doi: 10.1177/1468794118787711]

82. Laconi S, Rodgers RF, Chabrol H. The measurement of Internet addiction: a critical review of existing scales and their psychometric properties. Comput Human Behav 2014 Dec;41:190-202. [doi: 10.1016/j.chb.2014.09.026]

83. Sigerson L, Cheng C. Scales for measuring user engagement with social network sites: a systematic review of psychometric properties. Comput Human Behav 2018 Jun;83:87-105. [doi: 10.1016/j.chb.2018.01.023]

84. Cheng C, Cheung MW, Wang H. Multinational comparison of internet gaming disorder and psychosocial problems versus well-being: meta-analysis of 20 countries. Comput Human Behav 2018 Nov;88:153-167. [doi: 10.1016/j.chb.2018.06.033]

85. Ho RC, Zhang MW, Tsang TY, Toh AH, Pan F, Lu Y, et al. The association between internet addiction and psychiatric co-morbidity: a meta-analysis. BMC Psychiatry 2014 Jun 20;14:183 [FREE Full text] [doi: 10.1186/1471-244X-14-183] [Medline: 24947851]

86. Alimoradi Z, Lin C, Imani V, Griffiths MD, Pakpour AH. Social media addiction and sexual dysfunction among Iranian women: the mediating role of intimacy and social support. J Behav Addict 2019 Jun 01;8(2):318-325 [FREE Full text] [doi: 10.1556/2006.8.2019.24] [Medline: 31120317]

87. Benson V, Hand C, Hartshorne R. How compulsive use of social media affects performance: insights from the UK by purpose of use. Behav Inf Technol 2018 Oct 26;38(6):549-563. [doi: 10.1080/0144929x.2018.1539518] 
88. Cheng C, Ebrahimi OV, Lau Y. Maladaptive coping with the infodemic and sleep disturbance in the COVID-19 pandemic. J Sleep Res 2021 Aug;30(4):e13235 [FREE Full text] [doi: 10.1111/jsr.13235] [Medline: 33247519]

89. Brailovskaia J, Margraf J. The relationship between burden caused by coronavirus (Covid-19), addictive social media use, sense of control and anxiety. Comput Human Behav 2021 Jun;119:106720 [FREE Full text] [doi: 10.1016/j.chb.2021.106720] [Medline: 33785982]

90. Cheng C, Wang H, Ebrahimi OV. Adjustment to a "New Normal:" coping flexibility and mental health issues during the COVID-19 pandemic. Front Psychiatry 2021 Mar 19;12:626197 [FREE Full text] [doi: 10.3389/fpsyt.2021.626197] [Medline: 33815166 ]

91. Cheng C, Cheung MW, Montasem A, 44 members of the International Network of Well-Being Studies. Explaining differences in subjective well-being across 33 nations using multilevel models: universal personality, cultural relativity, and national income. J Pers 2016 Feb;84(1):46-58. [doi: 10.1111/jopy.12136] [Medline: 25234240]
Abbreviations
BSMAS: Bergen Social Media Addiction Scale
DSM: Diagnostic and Statistical Manual of Mental Disorders
ICD: International Statistical Classification of Diseases and Related Health Problems
LPA: latent profile analysis

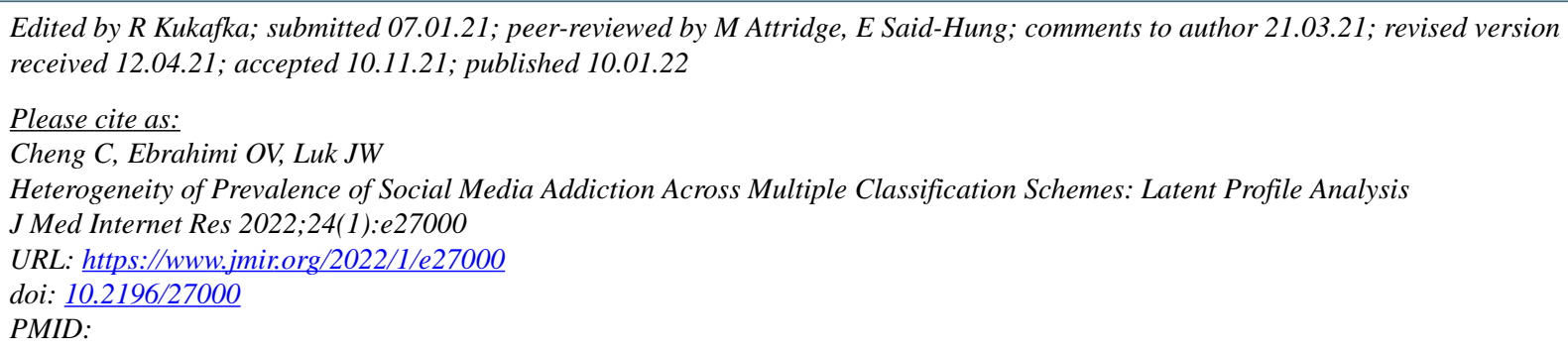

(C)Cecilia Cheng, Omid V Ebrahimi, Jeremy W Luk. Originally published in the Journal of Medical Internet Research (https://www.jmir.org), 10.01.2022. This is an open-access article distributed under the terms of the Creative Commons Attribution License (https://creativecommons.org/licenses/by/4.0/), which permits unrestricted use, distribution, and reproduction in any medium, provided the original work, first published in the Journal of Medical Internet Research, is properly cited. The complete bibliographic information, a link to the original publication on https:/www.jmir.org/, as well as this copyright and license information must be included. 